\title{
Development of The Automatic Control System Based on Human Machine Interface
}

\author{
M. Khairudin, F. Surwi \\ Dept. of Electrical Engineering Education \\ Yogyakarta State University \\ Yogyakarta, Indonesia \\ moh_khairudin@uny.ac.id, faranita@uny.ac.id
}

\begin{abstract}
The development of the industrial automation technology has led to the control system based on human machine interface (HMI) that allows the monitoring system by the user. Automatic control based on HMI emphasizes monitoring techniques in real time for the plant's performance through the monitor screen or LCD. This paper presents the design of automatic control system based on HMI to increase the user convenience while controlling the plant. This study finds a solution about the automatic control system based on HMI for monitoring a plant's performance remotely using the LCD screen, so it can help and facilitate the user, particularly by the features: (1) enable to monitor a plant condition through visualization of the real time status, (2) controlling the values of plant's parameter remotely. This study uses a research and development method, which each stage of the sub-systems will be assisted for improving the overall system's performance so can obtain in accordance with the desired system. The results show that the developed system can perform to select objects based on the object's color, those are red, white and silver. Also it can distinguish the workpiece of metal and non-metal. All processes of the object selection can be monitored through the monitor's screen.
\end{abstract}

Keywords- human machine interface; automatic control system; user

\section{INTRODUCTION}

Several features services to conduct the monitoring and supervision become indispensable to give smart solutions. The monitoring and supervision can be conducted not only for the production process and construction,but it should be conducted in a safe place and independent to the production plant which was being proceed, the transfering objects and selection or sorting of materials and products.

It is caused there are several factors that influence the plant process, including supervision and monitoring process that should take a place in an independent area, automatic supervisory and monitoring by user (operator, technician and engineer) from operator room. It is quite possible the production process that carried out by the plant occurs in dangerous environments for users (operators, technicians and engineers) so it should be monitored from a safe area.
The ease of controlling and monitoring process and can make the decision to control over the plant which was proceed the production in a certain distance can occur if there is a connection or often called the interface between user (operators, technicians and engineers) and the plant or machine.

The process that connects the plant which has been processing and the operators, technicians and engineers can be called as a human machine interface.

This study attempts to bridge the gap between the expected features in today's society to the condition of the control system which is still relatively conventional, that requires operators at the plant locations. This study is the design of the prototype of automatic control system based on a HMI for (1) monitoring conditions of plant through visualization of real time status, and (2) to control a parameter of plant from long distance.

Mohamed et al. [1] presented the modelling and development of a robust control algorithm of a two-link flexible manipulator, and for control of the system, a Linear Matrix Inequality (LMI)-based robust Proportional Derivative (PD) controller is developed and analysed. For performance comparison, PD controller based on a closed-loop ZieglerNichols (ZN) technique is also designed. The performances of the controller are examined in terms of input tracking capability, level of deflection of both links and robustness to various payload conditions [2].

Sutiawan et.al. [3] describes an automatic control system based on HMI has several advantages i.e. suitable for a flexible region, practical and does not require a lot of labor because it uses automation systems, more cheaper investment, more easy to control because it uses computerisation and more eficient and faster for finding and solving the job.

Choosing the process uses automation control system based on HMI for practical application, because this interfacing provides several facilities and flexibilities. Moreover, Khairudin et.al. [4] presents the effects of varying payload on the dynamic characteristics of the system. The dynamic model have been carried out in the time and frequency domains where the system responses including angular positions, modal displacements and end-point 
acceleration are studied. It is found that the payload significantly affected by the system behaviour. These results were very helpful and important in the development of the effective control algorithms for a two-link flexible robot manipulator incorporating payload.

Gruhn [5] shows the HMI designs have been identified as factors for contributing to abnormal situations, more investments of lost production, accidents, and fatalities. Also several HMIs actually impede rather than assist operators and holdovers due to the limitations of early control systems and the lack of knowledge of system designers.

HMI shows the data to the operator and provides an input of control system for user (operator, technician, and engineer) in the several forms, included charts, schematically, windows, menu of pull-down, touch screen, and other features. The function of Master Terminal Unit (MTU) is to display data on users (operator, technician, and engineer) through HMI, to collect data from long distance, and send control signal to the plant in long distance. The velocity of data transmission from MTU and plant on long distance is relatively low. Generaly, control system method's use open loop because the possibility of delay time and flow interruption [3].

Commonly, an automatic control system consists of plant, sensor, and controller [6]. In the progress, the components of automatic control system based on HMI as presented in Figure 1. The components of automatic control system based on HMI consists of: (1) Sensor and actuator (field device), (2) Remote Terminal Unit, (3) Communication system, (4) Master Terminal Unit.

Fiset [7] presented Human Machine Interface (HMI) is the system used by user for monitoring and controlling the plant from a long distance in industry. With another definition, HMI is interfacing between user and manufacturing machine in industry.

In industrial control automation, selection process and sorting the product are parts of the industrial job that have to be done. Emir Nasrullah, et.al [8] describes sorting process and charging products in the several company using conveyors that equipped with sensing and counting process to facilitate filling the product.

\section{RESEARCH METHOD}

This study is closed by research and development method. In the implementation, this study consists of two stages. First, development stage, that is development of an automatic control system based on HMI to conduct monitoring the plant through visualization in real time for selecting and sorting an object. Second the development of an automatic control system based on HMI to control the value of plant's parameter from a long distance.

\section{THE RESULTS AND ANALYSIS PREPARE}

This study conducted the development of the plant for sorting and selecting station. For developing the sorting and selecting plant, it is necessary several components that consists of electronics and mechanics. The process of designing mechanical sorting station using Solidwork software to create a 3D picture of a conveyor sorting station. The mechanical design using Solidwork software can be seen at Fig. 1.

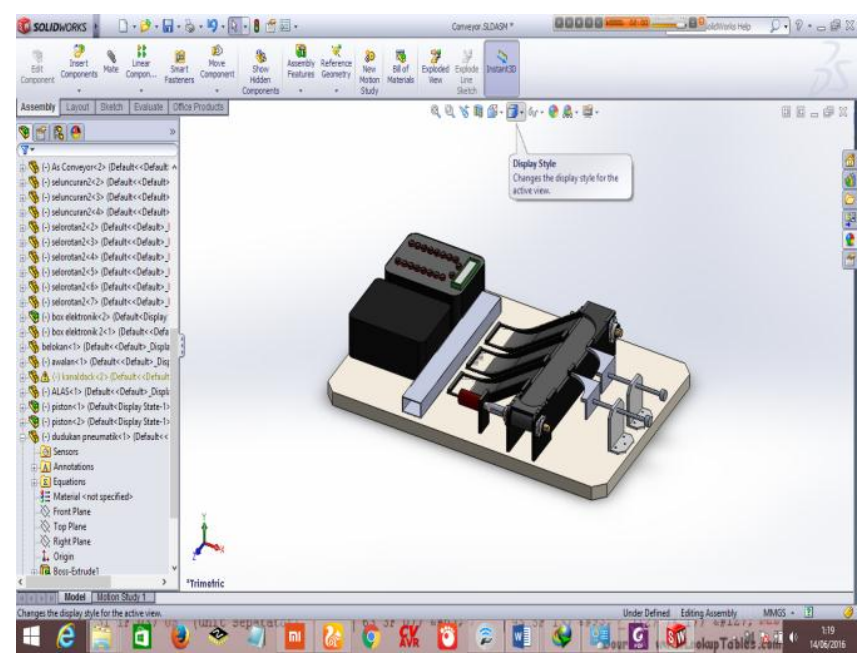

Fig. 1. Mechanical Design of Sorting Station

In preparation of the hardware consists of several main components so it can do selecting objects based on color and type of metal. Several of the important electronic components are: data processing, sensor and actuator.

The minimum system is an important part of components for building the sorting station. It is the main processor to control the sorting station based on Atmega 32 microcontroller. The minimum system can be supplied using 5 to $12 \mathrm{DC}$ voltages.

The minimum system also is equipped with an LCD driver and comes with port downloader that can be used to change and update the program. Fig. 2 shows the design of the microcontroller minimum system.

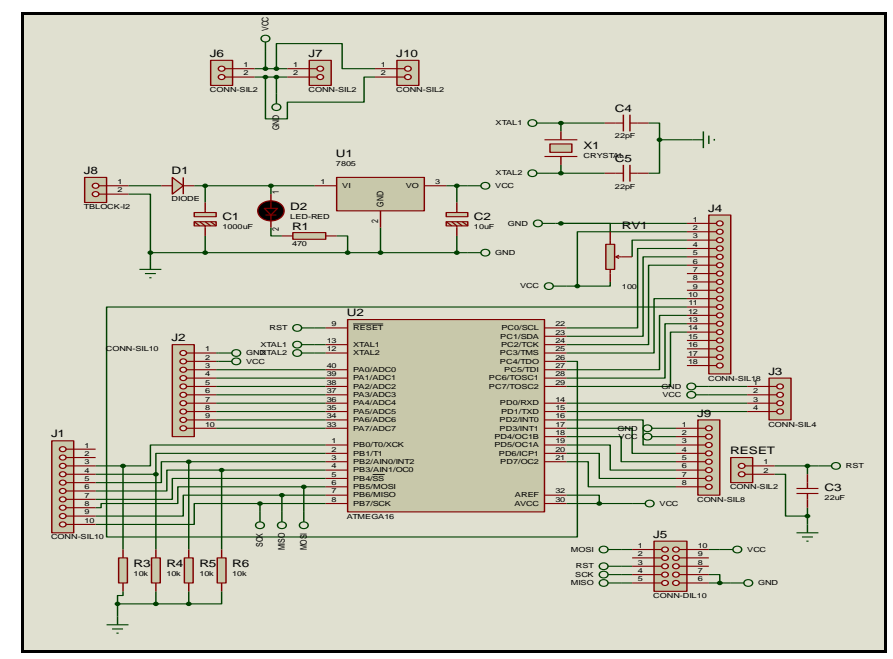

Fig. 2. The Minimum System Schematic 
In other hand, USB to Serial is a circuit that used to connect a microcontroller and personal computer (PC). Transmitting data using serial data with two lines of $\mathrm{Rx}$ and Tx, thusit is converted by this circuit into USB signal so that signal can be sent to the computer via USB port. The USB to Serial circuit uses a firmware of CDC 232 from Atmega8. Fig. 3 depicts the circuit and layout of the USB to Serial CDC 232.

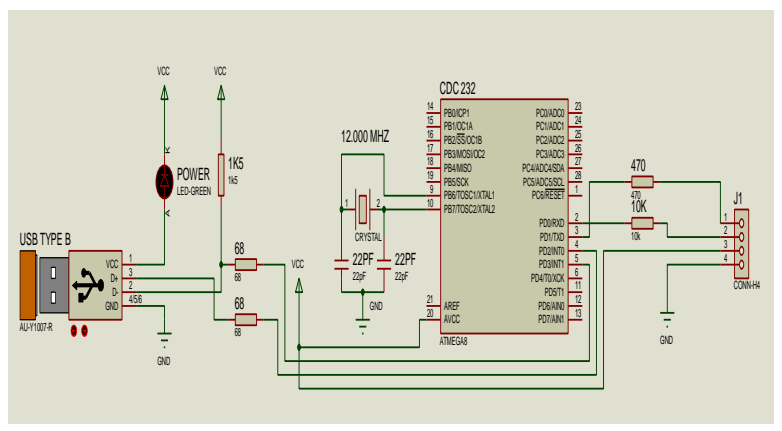

Fig. 3. The USB to Serial CDC 232 Schematic Diagram

The next component is the circuit of motor driver for controlling the DC motor. The electronic circuit of motor driver uses IRF 540 mosfet as it is a N-channel mosfet for switching motor. Controlling the DC motor is programmed by the microcontroller using Pulse Width Modulation (PWM) principles. Fig. 4 presents the circuit of the motor driver.

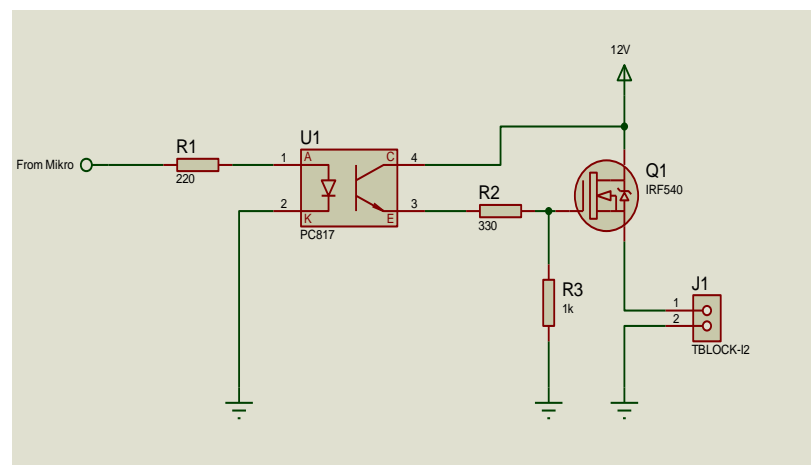

Fig. 4. The circuit of the motor driver

The sensors those are utilized to detect metal object namely inductive proximity sensor (metal sensor) and capacitive proximity sensor. The sensor for detecting the object's color is TCRT 3000. Otherwise, the actuator of the closed-open windows for sorting the object uses servo motor MG 550. The specification of the servo motor are the weight and body dimension are $55 \mathrm{~g}$ and $40.7 * 19.7 * 42.9$ $\mathrm{mm}$ respectively. Furthermore the torque stall, operation velocity and voltage are $10 \mathrm{~kg} / \mathrm{cm}, 0.20 \mathrm{sec} / 60$ degree $(4.8 \mathrm{v})$ and 4.8 to $7.2 \mathrm{~V}$ respectively.

Meanwhile, for designing the body conveyor uses transparant acrylic material with thick of $5 \mathrm{~mm}$ and using metal for the axis of conveyor. The pedestal of conveyor using plywood material with thick of $3 \mathrm{~mm}$ then it is organized into 3 layers. So that the overall board thickness is $9 \mathrm{~mm}$ and then given a silver gray color to create an impression of metal. Choosing the multiplex as the pedestal by considering the ease way while putting the conveyor on the pedestal. It only ses screws during installation.

Electronic board is used to place the arrangement of the electronic control of the sorting station. The designing of the electronic board uses a shaped beam acrilic box. In this design has two boxs those are the control box and power supply box respectively. The first box consists of banana plugs that functioned to control the output and read the input from sorting station. Besides it, the control board also contains the minimum system, USB to serial and LCD. Other, the power supply board contains a power supply, motor driver and terminal blocks.

Electronic circuits were used to connect several parts of system in this design. The main control equipments and components that must be connected each other are the minimum system, power supply, sensors, actuators, and the downloader. Installation of the electronic circuit for the sorting station using duck channel and spriral cable. Sensor and actuator were connected each other by terminal.

In order hand, the design of HMI is conducted by designing the window interface that consists of several forms namely: main form, profile form, and material form. The main form is used to control and monitoring the sorting station. Fig. 5 shows the design of the main form for the window interfacing.

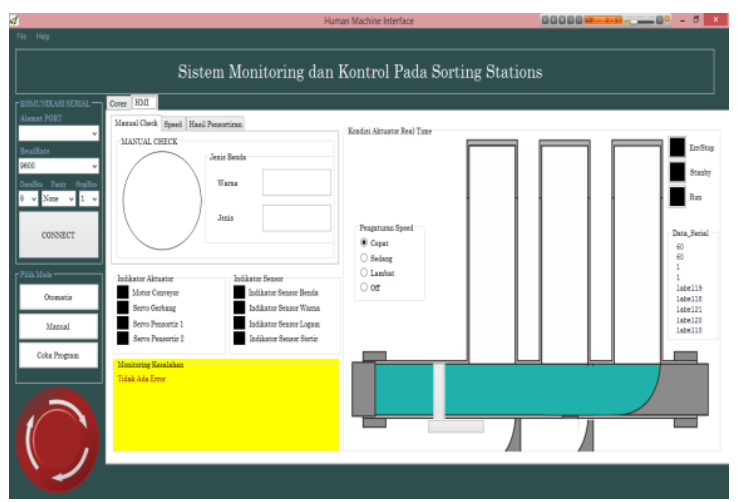

Fig. 5. The Main Form Window

The main form consists of several features to control and monitoring the sorting station. The features of the HMI software are as follows: Communication Setting, Mode Selection, Emergency Stop, Objects Monitoring, Motor Speed Monitoring, Input/Output Monitoring, Number of objects Monitoring at Sorting station, Speed control, Error Monitoring, Actuator Performance Monitoring, and Monitoring of the Sorting Station Condition.

Table 1 presents the performances of sorting station with control system based on HMI: 
TABLE I. THE PERFORMANCES OF SORTING STATION BASED ON HMI

\begin{tabular}{|c|c|c|c|c|}
\hline Color & $\begin{array}{c}\text { Object } \\
\text { detected }\end{array}$ & $\begin{array}{c}\text { ADC } \\
\text { Sensor }\end{array}$ & $\begin{array}{c}\text { Color } \\
\text { detected }\end{array}$ & Placement \\
\hline white & Nonmetal & 134 & white & 2 \\
\hline white & Nonmetal & 120 & white & 2 \\
\hline white & Nonmetal & 123 & white & 2 \\
\hline red & Nonmetal & 50 & red & 1 \\
\hline red & Nonmetal & 55 & red & 1 \\
\hline red & Nonmetal & 55 & red & 1 \\
\hline red & Nonmetal & 50 & red & 1 \\
\hline Silver & Metal & 108 & Silver & 3 \\
\hline Silver & Metal & 106 & Silver & 3 \\
\hline Silver & Metal & 100 & Silver & 3 \\
\hline
\end{tabular}

Based on these results, the performances of the control system of sorting station can operate in accordance with the predetermined specifications. Likewise with the control function of HMI has operated in accordance with the predetermined specifications.

\section{CONCLUSION}

The design of the automatic control system based on HMI has been conducted and can work in accordance to the predetermined specifications. The design and development of the sorting station has been conducted and realized.. The performance of the controller has been evaluated in terms of color detection capabilities and metal detection. Experimental results envisaged that the automatic control system based on HMI can detect the color and material object according to the real object.

\section{REFERENCES}

[1] Mohamed Z., M. Khairudin, A.R Husain, B. Subudhi, "Linear matrix inequality-based robust proportional derivative control of a two-link flexible manipulator", Journal of Vibration anc Control, Vol. 22(5) 1244-1256, 2016.

[2] M. Khairudin, "Quantitative Feedback Theory-Based Robust Control For A Spindle Of Lathe Machine", International Journal on Smart Sensing and Intelligent Systems, Vol.9 No. 4, December 2016

[3] Sutiawan Tresno, Sri Poernomo Sari, Nur Sultan Salahuddin, Fitrianingsih, "Prototipe Sistem Parkir Bertingkat Otomatis Berbasis Programmable Logic Controller Dan SCADA-HMI”. Prosiding Seminar Ilmiah Nasional Komputer dan Sistem Intelijen (KOMMIT 2014). Vol. 8 October 2014 Universitas Gunadarma, Depok - 14-15 October 2014.

[4] M. Khairudin, Z. Mohamed, A. R. Husain and M. A. Ahmad, "Dynamic modelling and characterisation of a two-link flexible robot manipulator", Journal Of Low Frequency Noise, Vibration And Active Control, Vol. 29 No. 3, 2010, $207-219$

[5] Gruhn PE, "Human Machine Interface (HMI) Design: The Good, The Bad, and The Ugly", 66th Annual Instrumentation Symposium for the Process Industries January 27-29, 2011.

[6] Ogata Katsuhiko, "Modern Control Engineering. 4th Edition". Prentice Hall, New Jersey. 2002.

[7] Fiset, Jean-Yves, "Human-Machine Interface Design for Process Control Applications", North Carolina: ISA.

[8] Emir Nasrullah, Agus Trisanto, dan Kurnia Ramdhani, "Model Sistem Kontrol Pemilahan Produk Berbentuk Kotak", Jurnal Ilmiah Elite Elektro, Vol. 3, no. 1, March 2012: 49-58. 